\title{
Editorial: Strategic and policy making issues in information literacy
}

John Crawford

\section{Introduction}

Welcome to this special issue of Library and Information Research. The papers presented here are the outcome of a call for papers circulated via a wide range of e-lists in January 2016. The call for papers solicited articles for a special issue on information literacy focussing particularly on strategic and policy making issues in information literacy, both in the UK and worldwide. In the event all the offered papers originated within the UK. They range widely over a variety of issues and demonstrate how the scope of information literacy has extended in recent years from its original base in education and particularly in higher education. Six contributions are presented here; two opinion pieces and four refereed research articles. The authors are thanked for the time they have given to the work as some have other substantial commitments. There is a strong devolutionary element as half of the papers are concerned to a greater or lesser extent with Scotland, including recent political events, while a fourth is concerned with Wales. The scope of information literacy is therefore extended to include the politics of devolution and what it implies.

\section{Papers}

The first opinion piece is 'Ageing and Information: The Scottish Older People's Movement' by Bill Johnston, who writes from the perspective of both an information literacy activist and chair of the Scottish Senior's Alliance. He argues that information literacy needs to be become integral to many aspects of older people's lives but the bewildering variety of sources available represents a barrier to achieving this. Lack of research in this area is also a problem. He offers a potential strategy but notes that there is no single focus for addressing older people's issue within the Scottish Government. Although reflecting the Scottish experience this article will be useful to people in other jurisdictions.

The second opinion piece - 'Information literacy as a tool to support political participation' - is by Lauren Smith draws on her research into the use of

\section{Author}

John Crawford is an independent libraries professional and founder chair of Information Skills for a $21^{\text {st }}$ Century Scotland.

Email: johncrawford705@yahoo.co.uk 
information by young people, and particularly their use of information for political decision making. Again this draws on the Scottish experience as in Scotland 16-17 year olds were able to vote in the 2014 referendum. She writes in the context of the 2014 Scottish Independence Referendum, the 2015 General Election and the 2016 European Referendum and argues that teenagers' political development is an important feature of democratic systems. However it is unclear whether school pupils have the information skills to address this issue. Inter alia she discusses the role of librarians in supporting school pupils.

In the first of four reviewed research articles Lynne Cole, Andrew MacFarlane and George Buchanan, in a methodologically complex paper, discuss 'Does dyslexia present barriers to information literacy in an online environment? A pilot study'. This researches the online searching behaviour of a small number of female dyslexics, testing their skills against the SCONUL Seven pillars. Not surprisingly dyslexics were found to have problems with searching, and there are also self-efficacy issues. There is scope for much more research here.

In 'Information literacy development in a small country: a practical proposition?' I review the development of information literacy activity in Scotland, particularly in relation to policy making, concentrating on the period after 2012 when the online community of practice, The Right Information: Information Skills for a $21^{\text {st }}$ Century Scotland, was founded. While recruiting activists, getting the support of professional bodies and engaging with a wide range of collaborators and supporters from other professionals and interest areas has been successful, resourcing is a continuing problem and activity is seriously under bureaucratised. Basing information literacy advocacy on a wide range of policy documents including those produced by the Scottish Government has proved to be a key activity. The agenda finds echoes with the work of Lauren Smith and Bill Johnston.

In 'Between digital inclusion and social equalities: the role of public libraries in Newcastle upon Tyne' Maria Laura Ruiu and Massimo Ragnedda report on an interview and observation based study which explores the role public libraries play in challenging digital inequalities and the problems they face in doing so. This is done via a study of public libraries in Newcastle, a service which has suffered budget cuts and the closure of council run libraries. Identifying libraries in four deprived areas they report on how staffs work to reduce digital inequality in a climate of diminishing resources. Partnership working and the recruitment of digital champions are found to be important factors. Although limited to Newcastle there are lessons here which other towns and cities can learn.

In the final article - 'Information Literacy and Information Seeking of Public Sector Managers in the Welsh Government' - Elizabeth Tait and Robert Edwards undertake research into the information seeking and information literacy of public sector managers in the Welsh Government. Workplace information literacy studies are still under represented in the literature and this article is a welcome addition. The findings are based on 23 interviews. Findings include reliance on a few trusted sources and other colleagues, limited awareness of the services available and reluctance to receive information literacy training. These findings 
will be of interest to and will resonate with public sector information professionals in other jurisdictions.

\section{Open access and copyright}

Library and Information Research is an open access journal. A freely available copy of this paper may be downloaded from the journal's website: http://www.lirgjournal.org.uk.

Copyright and associated moral rights in works published in Library and Information Research are retained by the author(s) but this paper may be used freely, with proper attribution, in educational and other non-commercial settings. 